\title{
BMJ Open Chronic diseases and multimorbidity among unemployed and employed persons in the Netherlands: a register- based cross-sectional study
}

\author{
Berivan Yildiz (D) , ${ }^{1}$ Merel Schuring, ${ }^{1}$ Marike G Knoef, ${ }^{2}$ Alex Burdorf (D) ${ }^{1}$
}

To cite: Yildiz B, Schuring M, Knoef MG, et al. Chronic diseases and multimorbidity among unemployed and employed persons in the Netherlands: a register-based cross-sectional study. BMJ Open 2020;10:e035037. doi:10.1136/ bmjopen-2019-035037

- Prepublication history and additional material for this paper are available online. To view these files, please visit the journal online (http://dx.doi. org/10.1136/bmjopen-2019035037).

Received 16 0ctober 2019 Revised 21 April 2020 Accepted 03 June 2020

Check for updates

(C) Author(s) (or their employer(s)) 2020. Re-use permitted under CC BY. Published by BMJ.

${ }^{1}$ Department of Public Health, Erasmus University Medical Center, Rotterdam, The Netherlands

${ }^{2}$ Department of Economics, Leiden University, Leiden, ZuidHolland, The Netherlands

Correspondence to

Dr Merel Schuring;

m.schuring@erasmusmc.nl

\section{ABSTRACT}

Objectives The first objective of this study was to describe the age-specific prevalence of chronic diseases and multimorbidity among unemployed and employed persons. The second objective was to examine associations of employment status and sociodemographic characteristics with chronic diseases and multimorbidity. Design Data linkage of cross-sectional nationwide registries on employment status, medication use and sociodemographic characteristics in 2016 was applied. Setting Register-based data covering residents in the Netherlands.

Participants 5074227 persons aged 18-65 years were selected with information on employment status, medication use and sociodemographic characteristics. Outcome measures Multiple logistic regression analysis and descriptive statistics were performed to examine associations of employment and sociodemographic characteristics with the prevalence of chronic diseases and multimorbidity. The age-specific prevalence of six common chronic diseases was described, and Venn diagrams were applied for multimorbidity among unemployed and employed persons.

Results Unemployed persons had a higher prevalence of psychological disorders (18.3\% vs $5.4 \%$ ), cardiovascular diseases $(20.1 \%$ vs $8.9 \%)$, inflammatory diseases $(24.5 \%$ vs $15.8 \%)$ and respiratory diseases ( $11.7 \%$ vs $6.5 \%)$ than employed persons. Unemployed persons were more likely to have one (OR $1.30(1.29-1.31))$, two (OR 1.74 (1.73-1.76)) and at least three chronic diseases (OR 2.59 (2.56-2.61)) than employed persons. Among unemployed persons, psychological disorders and inflammatory conditions increased with age but declined from middle age onwards, whereas a slight increase was observed among employed persons. Older persons, women, lower educated persons and migrants were more likely to have chronic diseases.

Conclusion Large differences exist in the prevalence of chronic diseases and multimorbidity among unemployed and employed persons. The age-specific prevalence follows a different pattern among employed and unemployed persons, with a relatively high prevalence of psychological disorders and inflammatory conditions among middle-aged unemployed persons. Policy measures should focus more on promoting employment among unemployed persons with chronic diseases.

\section{Strengths and limitations of this study}

- This is the first study that describes the prevalence of chronic diseases and multimorbidity among unemployed and employed persons, using objective register-based data rather than self-reported health outcomes.

A strength of this study is applying data linkage of nationwide registries that capture the whole population, facilitating precise estimations of associations between health and employment, and offering us the possibility to investigate specific subgroups (age-specific prevalence).

- Except for back pain and musculoskeletal disorders, this study investigated a broad range of chronic diseases such as cardiovascular diseases, psychological disorders, diabetes and respiratory diseases.

- Causal effects of having a chronic disease on employment status, or vice versa cannot be distinguished because of the use of cross-sectional data and the bidirectional nature of health and employment.

\section{INTRODUCTION}

The relationship between unemployment and health has been well established. ${ }^{12}$ In general, unemployed individuals have worse mental and physical health compared with employed individuals. ${ }^{2-5}$

These health inequalities between employed and unemployed persons can be explained by two different hypotheses. First, according to the causation hypothesis, persons who become unemployed will deteriorate in health, whereas unemployed persons who enter paid employment will improve in health. ${ }^{6}$ Second, the selection hypothesis describes that persons who leave paid employment already have lower levels of health before leaving employment compared with those who remain employed, whereas persons who enter paid employment already have a better health status before entering 
employment compared with persons who remain unemployed. ${ }^{7}$

Chronic diseases can affect an individual's employment status due to experienced functional limitations and a poor-quality of life. ${ }^{8}$ Two studies have shown that longterm health conditions such as cardiovascular diseases and diabetes were associated with unemployment. ${ }^{9}{ }^{10} \mathrm{In}$ addition, a recent systematic review provided evidence that individuals with diabetes were more likely to be out of the labour force. ${ }^{9}$ However, studies investigating chronic diseases and employment have mostly focused on a single disease, whereas many persons with a chronic disease are likely to suffer from multiple chronic diseases, especially among older age groups. There is increasing evidence that persons with multimorbidity-the co-occurrence of at least two chronic diseases within an individual-may be more likely to have poorer functional outcomes and thus may be also more often out of the labour market than those with a single chronic disease or no chronic disease. For instance, a study among Australian workers with multiple health problems showed that individuals with four or more health problems were far less likely to be employed compared with those with no health condition. ${ }^{11}$ Another study among persons with back complaints found that the co-occurrence of cardiovascular diseases resulted in a 10-fold increased risk of unemployment compared with those with back complaints alone. ${ }^{12}$

So far, findings on the association of chronic diseases and multimorbidity with unemployment have been based mostly on self-reported health outcomes. Self-reported health outcomes are known to be vulnerable to reporting bias and justification bias. Therefore, a more objective approach is preferred in order to make more precise estimations of the prevalence of diseases. One way to objectively investigate the presence of chronic diseases is by using pharmacy data. ${ }^{13}$ Pharmacy data provide a reliable information source and often cover a large population. ${ }^{14}$ Administrative databases such as drug prescription can be used to identify persons with chronic diseases. So far, only a few studies have used register-based data in order to investigate chronic diseases among unemployed persons. A Danish register-based study found a higher prevalence of mental disorders and cardiovascular disorders among unemployed persons receiving social benefits compared with employed persons. ${ }^{15}$ In line with this, another register-based study showed that long-term unemployment was associated with a higher risk of antidepressant use. $^{16}$

To our knowledge, none of the evidence on the association between multimorbidity and employment status has been based on register-based data. Therefore, the present study aimed to investigate the prevalence of chronic diseases and multimorbidity among unemployed and employed persons. The large register data enabled to investigate specific subgroups (eg, age-specific prevalences and associations). The second aim was to examine associations of employment status and sociodemographic characteristics with chronic diseases and multimorbidity.
Nation-wide data from the Netherlands on drug prescription, employment status and sociodemographic characteristics in 2016 were used.

\section{METHODS}

\section{Study population and design}

Register data covering information on all Dutch residents in 2016 were used. Statistics Netherlands provided individual-level databases on demographics, education, labour market status and prescribed medication. All Dutch residents were pseudonymised using a personal unique number. Data registries were linked at the individual level using these pseudonymised numbers. No informed consent was needed for this study since authorised research institutes in the Netherlands are by law allowed to use pseudonymised register-based data for research purposes.

Individuals aged between 18 and 64 years with available information on employment status were selected $(n=10$ 514271 ). This selection captured individuals who were not eligible for exit from paid employment through statutory national retirement schemes. Due to the lack of nationwide education registers in the past, many older persons had missing data on educational level. Also, the current register only includes formal education obtained at institutes financed by government. Therefore, we excluded $31.9 \%$ of individuals with missing data on educational level ( $n=3356002)$. Within the population with available data on all sociodemographic characteristics $(n=7158$ 269), 4566644 persons were classified as employed and 507583 persons were classified as unemployed. In total, 5074227 subjects were included in the present study.

\section{Employment status}

The database on social economic category per month provided information on employment status of participants for each month in the year 2016. The main source of income for each consecutive month was used to classify persons as employed or unemployed. Individuals who were in paid employment or self-employed for at least 9 months in 2016 were classified as employed $(n=4566$ $644)$. Individuals who were out of the labour market and received either social benefits or unemployment benefits for at least 9 months were classified as unemployed $(\mathrm{n}=507583)$.

\section{Chronic diseases and multimorbidity}

The database on medication use in 2016 (Medicijntab) provides information on purchased drugs that were reimbursed by the healthcare insurances. The drugs were identified using the WHO Anatomical Therapeutic Chemical (ATC) classification codes. ${ }^{17}$ In line with the study of Huber et al, specific chronic diseases were identified based on these ATC-codes. ${ }^{13}$ For instance, psychological disorders were identified by ATC-codes that were assigned to drugs such as antidepressants and anxiolytics, whereas inflammatory conditions were identified 
by the ATC-code that was assigned to non-steroidal antiinflammatory drugs (online supplementary table 1).

The presence of a specific chronic disease was dichotomised into having or not having a chronic disease. Multimorbidity was investigated as (1) the number of chronic diseases and (2) the combinations of four common chronic diseases with the highest prevalence in the study population. For the first approach of multimorbidity, the total number of chronic diseases was computed for each participant, based on 21 different chronic diseases that could be identified by medication prescription. ${ }^{13}$ This measure of multimorbidity was categorised into four groups: no chronic disease, one chronic disease, two chronic diseases and at least three chronic diseases. For the second approach, we used the following four chronic diseases to describe their co-occurrence: cardiovascular diseases, psychological disorders, inflammatory conditions and respiratory diseases.

\section{Sociodemographic variables}

The databases on sociodemographic characteristics provide information on age, gender, education and migration background. A dichotomous variable was computed for employment status (employed vs unemployed). Educational level was categorised into three educational groups: high (higher vocational training or university), intermediate (higher secondary and intermediate vocational training) and low education (pre-primary education, primary education and lower secondary education). Age was categorised into four age groups (18-30, 30-45, 45-55, 55-65). Migration background was categorised as native Dutch, Moroccan, Turkish, Surinamese and Antillean, other Western, and other non-Western.

\section{Analyses}

Descriptive statistics were used to describe the prevalence of chronic diseases and multimorbidity among employed and unemployed persons. The association of sociodemographic characteristics (age, sex, education and migration background) and employment status with (multiple) chronic diseases was examined using multiple logistic regression analysis in the total study population (employed and unemployed persons). Separate logistic regression analyses were done for each number of chronic diseases (dependent variable): (1) one chronic disease (2) two chronic diseases and (3) three or more chronic diseases. In these analyses, having no chronic diseases was used as the reference category. Logistic regression analyses were adjusted for age, sex, educational level and migration background. The association between employment status and multimorbidity stratified by age was also investigated. To test for possible selection bias, sensitivity analyses were performed by including individuals with missing data on educational level.

The prevalence of multimorbidity was also described as the proportion of individuals with all potential combinations of four exclusive chronic diseases. All combinations of co-occurrence between the four chronic diseases were presented in a Venn diagram for employed and unemployed persons. The age-specific prevalence of these four chronic diseases among unemployed and employed persons was presented. In order to distinguish specific conditions within a chronic disease, the age-specific prevalence of specific medicines was also investigated for cardiovascular diseases and psychological disorders. The latter was not investigated for the other chronic diseases because less specific medicines could be distinguished within the other chronic disease.

\section{Patient and public involvement}

No patients were involved.

\section{RESULTS}

Unemployed persons were more often older than 45 years $(58.2 \%)$, female $(54.5 \%)$, lower educated $(51.8 \%)$ and from non-Dutch origin $(48.1 \%)$ compared with employed persons (19.4\%). Differences in the prevalence of chronic diseases between unemployed and employed persons were highest for psychological disorders. Compared with employed persons, unemployed persons had a higher prevalence of psychological disorders (18.3\% vs 5.4\%), cardiovascular diseases $(20.1 \%$ vs $8.9 \%)$, inflammatory conditions (24.5\% vs $15.8 \%)$, psychotic illness $(6.2 \%$ vs $0.8 \%)$, respiratory diseases ( $11.7 \%$ vs $6.5 \%)$ and diabetes (7.2\% vs $2.0 \%)$. (table 1 )

The prevalence of multimorbidity was also higher for unemployed persons compared with employed persons. The co-occurrence of both psychological disorders and inflammatory conditions was higher among unemployed persons $(3.6 \%+0.9 \%+1.2 \%+0.5 \%=6.2 \%)$ than among employed persons $(1.0 \%+0.2 \%+0.2 \%+0.1 \%=1.5 \%)$. In addition, the co-occurrence of cardiovascular diseases and inflammatory conditions was higher among unemployed persons $(5.5 \%)$ compared with employed persons $(2.1 \%)$. The prevalence of having both cardiovascular diseases and psychological disorders was $4.9 \%$ among unemployed persons compared with $0.9 \%$ among employed persons (figure 1, online supplementary table 2).

At all ages, unemployed individuals had a higher prevalence of all four chronic diseases compared with employed individuals. The prevalence of psychological disorders increased with age followed by a decrease from middle age onwards among unemployed persons, whereas a slight increase was observed among employed persons. The same pattern was observed for inflammatory conditions. The prevalence of cardiovascular diseases and respiratory diseases increased with age among both unemployed and employed persons (figure 2).

Among unemployed persons, the use of antidepressants, anxiolytics and, hypnotics and sedatives was highest at middle age. The prevalence of antidepressants was higher than the use of anxiolytics, hypnotics and sedatives among unemployed persons for all age groups. The use of antithrombotic and cardiac agents, beta blockers 
Table 1 Characteristics of the study population by employment status

\begin{tabular}{lcc}
\hline & $\begin{array}{c}\text { Unemployed } \\
(\mathbf{n}=507583)\end{array}$ & $\begin{array}{c}\text { Employed } \\
(\mathbf{n}=4566 \text { 644) }\end{array}$ \\
\hline Age & $\mathrm{n}(\%)$ & $\mathrm{n}(\%)$ \\
\hline $18-30$ & $54807(10.8)$ & $1223211(26.8)$ \\
\hline $30-45$ & $157238(31.0)$ & $1808274(39.6)$ \\
\hline $45-55$ & $147865(29.1)$ & $1033090(22.6)$ \\
\hline $55-65$ & $147673(29.1)$ & $502069(11.0)$ \\
\hline Sex & $230856(45.4)$ & $2405740(52.7)$ \\
\hline Male & $276727(54.5)$ & $2160904(47.3)$ \\
\hline Female & $73893(14.6)$ & $2022717(44.3)$ \\
\hline Educational level & $170857(33.7)$ & $1906830(41.8)$ \\
\hline High & $262833(51.8)$ & $637097(14.0)$ \\
\hline Middle & & \\
\hline Low & & \\
\hline Migration background & & \\
\hline Native Dutch & $263196(51.9)$ & $3680071(80.6)$ \\
\hline Moroccan & $35441(7.0)$ & $76841(1.7)$ \\
\hline Turkish & $27131(5.3)$ & $97716(2.1)$ \\
\hline $\begin{array}{l}\text { Surinamese and } \\
\text { Antillean }\end{array}$ & $40446(8.0)$ & $145478(2.3)$ \\
\hline Other Western & $37420(7.4)$ & $311005(6.8)$ \\
\hline $\begin{array}{l}\text { Other non- } \\
\text { Western }\end{array}$ & $103949(20.5)$ & $255533(5.6)$ \\
\hline
\end{tabular}

Chronic diseases

\begin{tabular}{lcc}
$\begin{array}{l}\text { Inflammatory } \\
\text { conditions }\end{array}$ & $124411(24.5)$ & $721304(15.8)$ \\
\hline $\begin{array}{l}\text { Cardiovascular } \\
\text { diseases }\end{array}$ & $101917(20.1)$ & $405200(8.9)$ \\
$\begin{array}{l}\text { Psychological } \\
\text { disorders }\end{array}$ & $92956(18.3)$ & $248520(5.4)$ \\
\hline $\begin{array}{l}\text { Respiratory } \\
\text { diseases }\end{array}$ & $59557(11.7)$ & $296817(6.5)$ \\
\hline $\begin{array}{l}\text { Diabetes } \\
\text { Psychotic illness }\end{array}$ & $36662(7.2)$ & $89382(2.0)$ \\
\hline \begin{tabular}{l} 
No of chronic diseases \\
\hline 0
\end{tabular} & $193412(38.1)$ & $2877373(0.8)$ \\
\hline 1 & $118688(23.4)$ & $1007275(22.1)$ \\
\hline 2 & $79719(15.7)$ & $394396(8.6)$ \\
\hline 3 & $115764(22.8)$ & $287660(6.3)$ \\
\hline
\end{tabular}

and ACE inhibitors, and diuretics and calcium-channel blockers was highest among older unemployed and employed persons. The prevalence of beta blockers and ACE inhibitors, and antithrombotic agents was higher than diuretics and calcium-channel blockers, and cardiac agents among unemployed persons of all age groups (online supplementary figure 1).

Unemployed persons were more likely to have (multiple) chronic diseases compared with employed persons. Unemployed persons were more likely to have one (OR 1.30, 95\% CI 1.29 to 1.31 ), two (OR 1.74, 95\% CI 1.73 to 1.76 ) and at least three chronic diseases (OR 2.59, 95\% CI 2.56 to 2.61) than employed persons. Among unemployed persons, $23 \%$ had at least three chronic diseases compared with 6\% among employed persons. Women (OR $1.49,95 \%$ CI 1.49 to 1.50 ), older individuals (OR 1.32 to 2.27), middle and low educated persons (OR 1.32 to 1.49 ) and non-western migrants (OR 1.01 to 1.34) were also more likely to have a chronic disease. In addition, women (OR 1.61, 95\% CI 1.60 to 1.63 ), older persons (OR 2.72 to 17.08), lower educated persons (OR 2.11 to 3.32) and non-western migrants (OR 1.02 to $2.03)$ were also more likely to have multiple $(\geq 3)$ chronic diseases (table 2). Comparable results were found in sensitivity analyses on the total study population with inclusion of individuals who had missing data $(\mathrm{n}=7576$ 196) on educational level.

Within all age groups, unemployed persons had a higher risk of having one, two and at least three chronic diseases than employed persons. Especially, among persons aged 18-30 years, unemployed persons were more likely to have one (OR 1.65, 95\% CI 1.61 to 1.69), two (OR 2.84, $95 \%$ CI 2.75 to 2.93 ) and at least three (OR 5.20, 95\% CI 4.99 to 5.42) chronic diseases compared with employed persons. These effect estimates were lower among older age groups (online supplementary table 3 ).

\section{DISCUSSION}

In this large register-based study, unemployed persons had a higher prevalence of cardiovascular diseases, psychological disorders, inflammatory conditions, respiratory diseases and multimorbidity compared with employed persons. Between unemployed and employed persons, the largest differences were observed for cardiovascular diseases and psychological disorders. The prevalence of psychological disorders and inflammatory conditions was highest among unemployed persons in the middle age group. Women, older individuals, lower educated persons and non-western migrants were more likely to have one chronic disease as well as multiple chronic diseases. Among younger persons (18-30 years), a stronger association between chronic disease and unemployment was found compared with higher age groups.

The higher prevalence of chronic diseases among unemployed persons in the current study is in line with other studies showing that unemployed persons have a poorer mental and physical health status. ${ }^{2} 518$ For instance, unemployed persons had high risks of common mental disorders such as depression. ${ }^{19-21}$ Our study added to the current literature by comparing the agespecific prevalence of chronic diseases between unemployed and employed persons. Between unemployed and employed persons, the largest differences were observed for cardiovascular diseases and psychological disorders. Although the overall prevalence of cardiovascular diseases was much higher among unemployed persons, 
Unemployed

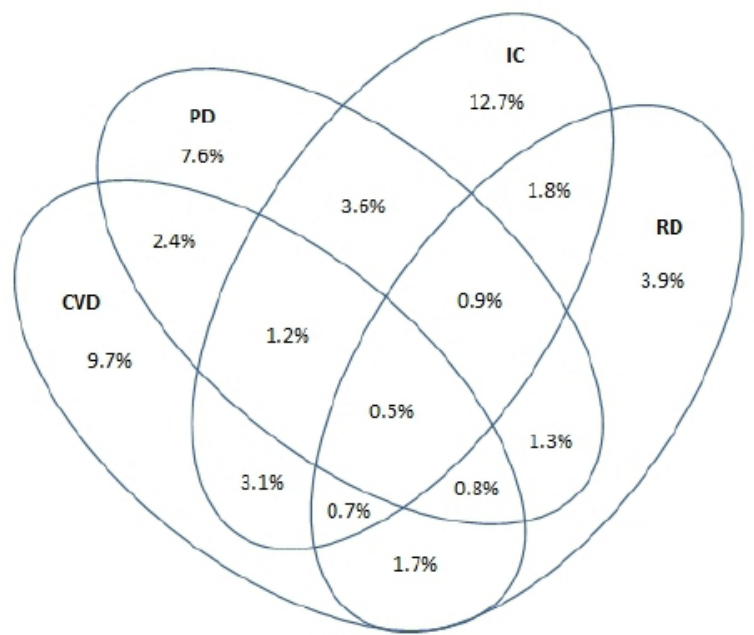

Employed

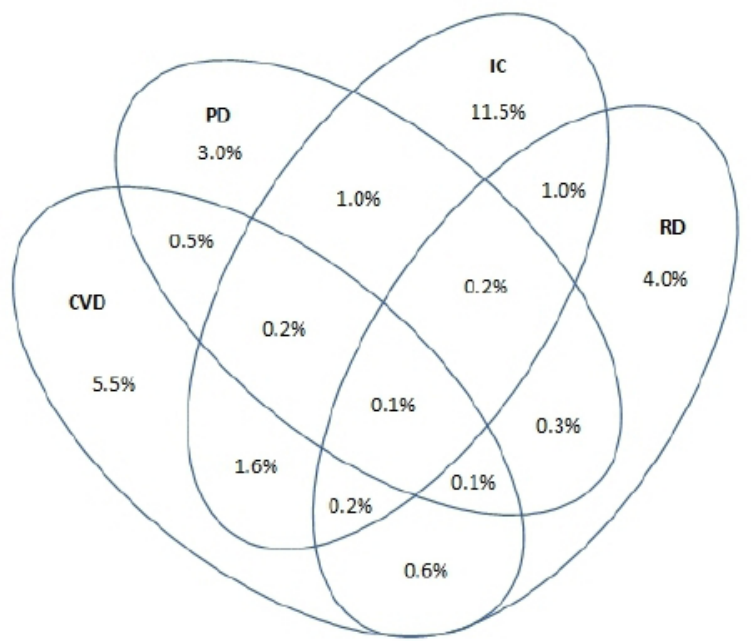

Figure 1 Multimorbidity of cardiovascular diseases (CVD), psychological disorders (PD), inflammatory conditions (IC) and respiratory diseases $(R D)$ among unemployed $(n=507583)$ and employed $(n=4566644)$ persons .

the age-specific patterns showed small differences, indicating that the higher age among unemployed persons was largely responsible for the higher prevalence of cardiovascular diseases.

A remarkable finding was the different pattern of the age-specific prevalence of psychological disorders between unemployed and employed persons. Among both employed and unemployed persons, the prevalence of psychological disorders increased with age. However, this increase was more profound among unemployed persons with a peak around middle age. This pattern among unemployed persons can be explained by studies arguing that before and after middle age, individuals tend to suffer less from unemployment compared with persons of middle age ${ }^{22}$ Persons of middle age often have family responsibilities, increasing the financial importance of a job, whereas younger and older persons experience less financial pressure and thus less psychological distress due to unemployment. ${ }^{23}$ The other way around, it can also be that the combination of family responsibilities and work lead to pressure and cause both health problems as well as unemployment. Furthermore, it has also been hypothesised that persons of middle age are more likely to aim for a successful career which leads to employment being more important for their mental health than it is for older persons who are almost finishing their careers, and for younger persons who have recently entered paid employment. ${ }^{24}$ The age-specific prevalence of antidepressants use, anxiolytics, and hypnotics and sedatives among unemployed persons confirms this theory by showing the highest prevalence at middle age and a lower prevalence at younger and older ages.

It was checked whether the decline in the prevalence of use of antidepressants, anxiolytics, hypnotics and sedatives after the age of 50 would be different among persons receiving a disability benefit. Namely, it might be possible that older unemployed persons with chronic diseases are more likely to receive disability benefits rather than unemployment or social benefits, and therefore the agespecific prevalence of these medicines declines among unemployed persons. However, also among persons with disability benefits, a decline was observed from middle age onwards for these medicines (results not shown).

Another interesting finding was an increase in the prevalence of inflammatory conditions with increasing age, followed by a decrease from middle age onwards among unemployed persons. This finding can be explained by the medicines NSAIDs that have been used to identify inflammatory conditions as a chronic disease in the present study. NSAIDs are pain killers with antiinflammatory effects and are known to cause serious adverse effects. ${ }^{25}$ Therefore, NSAIDs are cautiously or not prescribed among individuals aged 60 years or older, who suffer from cardiovascular diseases and already use other medicines for other (chronic) health conditions. ${ }^{26}$ In the present study, the prevalence of cardiovascular diseases and multimorbidity was higher among unemployed persons compared with employed persons. Thus, it may be that NSAIDs are less prescribed among older persons because of multimorbidity with cardiovascular disorders and associated polypharmacy-the use of multiple medicines. Therefore, the higher prevalence of multimorbidity among unemployed persons may explain the decrease in the prevalence of inflammatory conditions with increasing age.

Unemployed persons had a higher prevalence of multimorbidity than employed persons. It is likely that the healthy worker selection process is more prominent among persons with multiple diseases than single diseases. ${ }^{27}$ According to the causation mechanism, it 


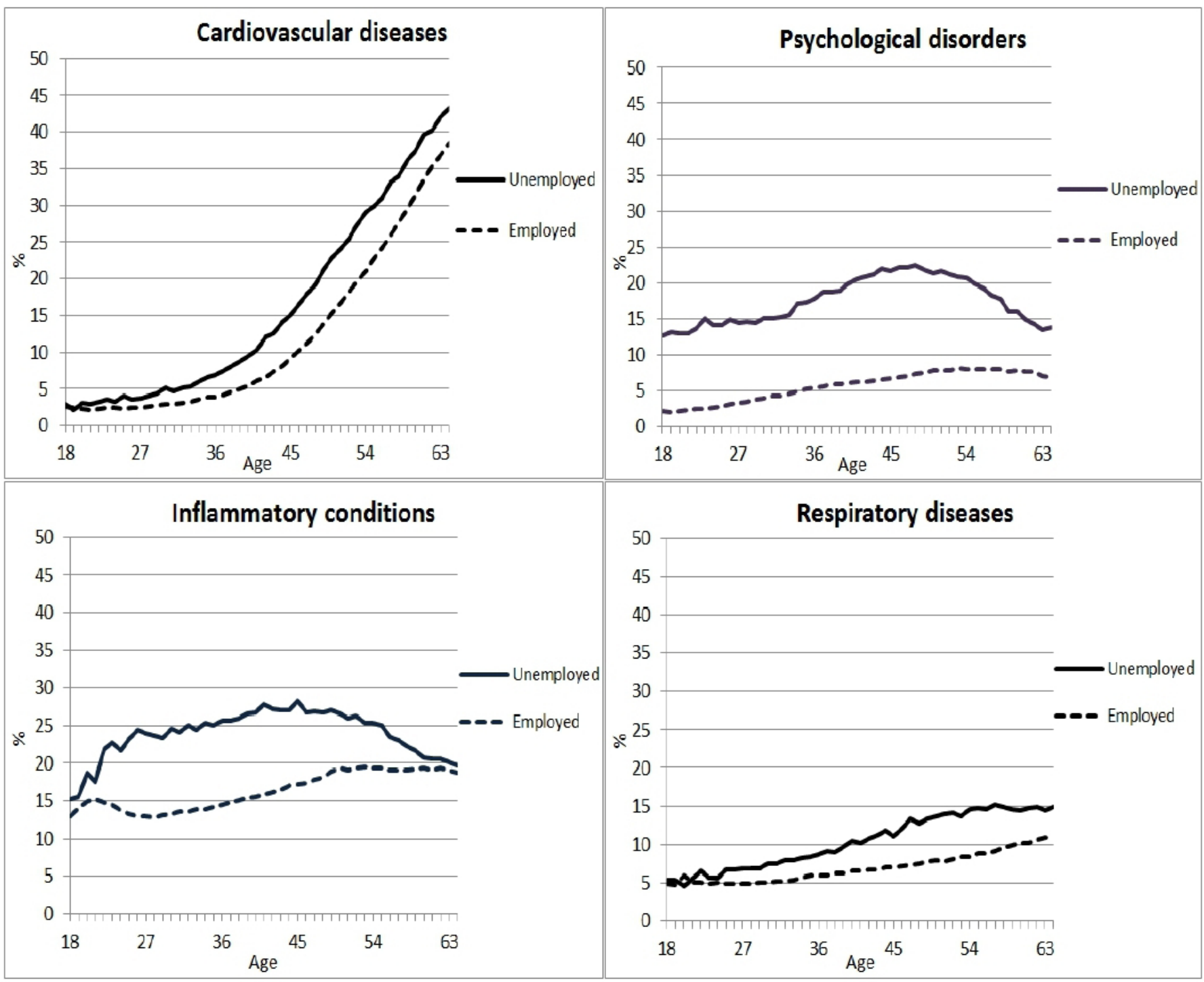

Figure 2 Prevalence of four chronic diseases by age among unemployed $(n=507583)$ and employed ( $n=4566644)$ persons in 2016.

could also be that persons who become unemployed will deteriorate in health. Underlying mechanisms have been proposed by Jahoda who posits that unemployed persons may lack five latent functions usually observed among employed persons such as a time structure, being useful, social contacts, social status and being active. ${ }^{28}$ The latter causation mechanism suggests that it is important that next to addressing chronic diseases, these psychosocial factors are targeted as well by interventions, in order to improve the health of unemployed persons. Improving health and employment opportunities for persons with chronic diseases is also important in the light of an ageing workforce with an expected increase of multimorbidity during the next decades.

The strength of the present study is the use of registerbased data, which is a more objective method to investigate the association between health and unemployment. In earlier studies, the relationship between health and unemployment has often been examined using selfreported outcomes of health and disability. ${ }^{18}$ However, a major concern of self-reported health outcomes is that unemployed individuals may over-report their level of disability or work limitations to justify that they are not in paid employment. ${ }^{29}$ In the current study, this problem has been minimised using register-based data on medication use that has been collected independently of the study. Another strength of the current study is that our register-based data capture the whole Dutch population and therefore the data provide statistical power to investigate age-specific prevalences. This facilitates precise estimations of associations between health and employment. Lastly, the use of register-based data is less expensive since no additional efforts have to be made for data collection and no concerns are present about health-related non-response.

Register-based data also have some limitations as the register only includes individuals who fulfil three criteria: (1) they are considered to need a particular drug by their general practitioner or specialist, (2) they purchase the prescribed medicine at the pharmacy and (3) the costs 


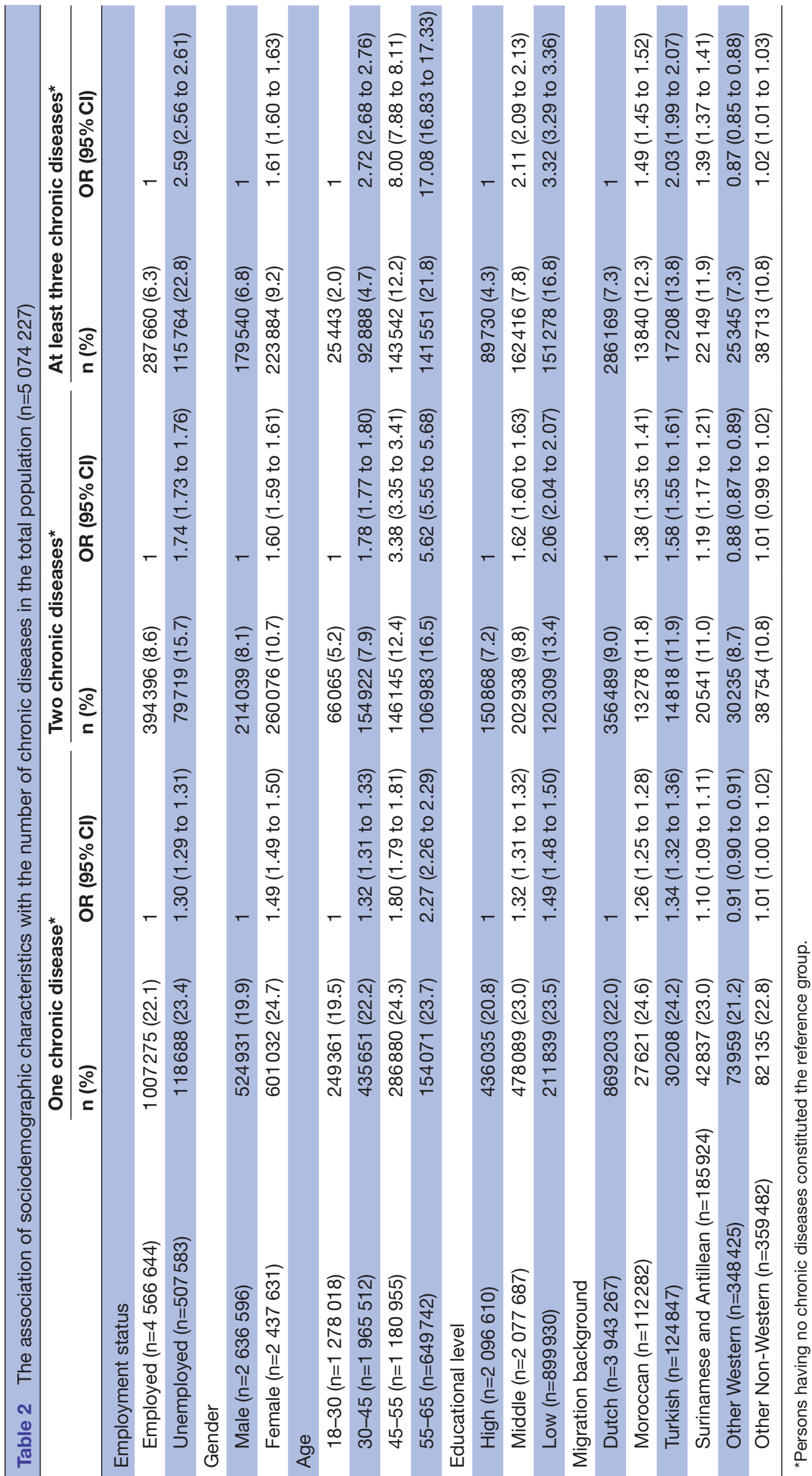


of the medicines are reimbursed by health insurances. For instance, persons with psychological disorders who are treated with a cognitive behavioural therapy rather than medication are not included in our analysis, and this may lead to an underestimation of persons with psychological disorders. Moreover, although a broad range of chronic diseases has been investigated in this study, several conditions that are associated with unemployment have not been included, such as back pain or musculoskeletal disorders. In the current study, it was not possible to identify these chronic conditions by the use of medication data. For instance, medication that is prescribed for back pain includes over the counter pain killers such as paracetamol or ibuprofen. However, since pain killers are used for various forms of bodily pain and no information was available regarding the reason of prescription, it was not possible to identify these health conditions. Nevertheless, it is possible that inflammatory conditions include musculoskeletal problems, as NSAIDs are a common treatment. ${ }^{26}$ Conditions such as back pain and musculoskeletal disorders are known to lead to exit from paid employment, and therefore, should be investigated among unemployed persons in future studies. ${ }^{12}$

A second limitation of this study was that the crosssectional design did not allow to gain insight into the bidirectional association between unemployment and health. However, this study provided pivotal evidence for the large differences in the prevalence of chronic diseases between unemployed and employed persons. Longitudinal or (quasi-) experimental studies are needed to further elaborate how chronic diseases lead to unemployment, and unemployment may result in chronic diseases and multimorbidity. A third limitation of this study relates to the selection of the study population of unemployed persons. Since the criteria for unemployment was defined as being unemployed for at least 9 months during a period of 1 year, our results and conclusions mainly apply to persons who are long-term unemployed. It may be that associations found in this study are less strong among short-term unemployed persons as they may have less health problems. Lastly, a limitation of the current study was the exclusion of individuals with missing data on educational level. Unemployed persons in this study more often had a lower educational level than employed person. Since there is an association between lower educational level and poorer health status, it was important to adjust for educational level in several statistical analyses. The sensitivity analysis showed comparable results in the total population and the population with educational information, indicating that education was most likely missing at random.

This study showed that health inequalities exist between unemployed and employed persons. Specifically, among the younger age group, a strong association of chronic diseases and multimorbidity with unemployment was found. Several studies have shown the beneficial effects of employment on health. ${ }^{30}$ According to these studies, interventions that can support unemployed persons with chronic diseases are needed to improve employment opportunities and thus health. In order to reduce health inequalities between unemployed and employed persons, it is therefore important that reintegration policies will focus more on promoting employment among unemployed persons with chronic diseases.

In conclusion, the current study showed that unemployed persons more often have chronic diseases and multimorbidity than employed persons. The age specific prevalence follows a different pattern among employed and unemployed persons, with a relatively high prevalence of psychological disorders and inflammatory conditions among middle aged unemployed persons. Policy measures are needed to improve health and promote employment among unemployed persons.

Contributors BY and MS prepared the data. BY performed the statistical analysis, drafted and revised the article. MS, MGK and AB participated in the analyses. MS, MGK and $A B$ critically reviewed the manuscript. All authors approved the final version.

Funding This study was funded by ZonMw (The Netherlands Organisation for Health Research and Development).

Competing interests None declared.

Patient consent for publication Not required.

Provenance and peer review Not commissioned; externally peer reviewed.

Data availability statement No data are available. This study used national registry data that can only be accessed by affiliated researchers through Remote Access.

Open access This is an open access article distributed in accordance with the Creative Commons Attribution 4.0 Unported (CC BY 4.0) license, which permits others to copy, redistribute, remix, transform and build upon this work for any purpose, provided the original work is properly cited, a link to the licence is given, and indication of whether changes were made. See: https://creativecommons.org/ licenses/by/4.0\%.

\section{ORCID iDs}

Berivan Yildiz http://orcid.org/0000-0002-2385-213X

Alex Burdorf http://orcid.org/0000-0003-3129-2862

\section{REFERENCES}

1 Janlert U. Unemployment as a disease and diseases of the unemployed. Scand J Work Environ Health 1997;23 Suppl 3:79-83.

2 McKee-Ryan F, Song Z, Wanberg CR, et al. Psychological and physical well-being during unemployment: a meta-analytic study. $J$ Appl Psychol 2005;90:53-76.

3 Bartley M, Sacker A, Clarke P. Employment status, employment conditions, and limiting illness: prospective evidence from the British household panel survey 1991-2001. J Epidemiol Community Health 2004;58:501-6.

4 Wanberg CR. The individual experience of unemployment. Annu Rev Psychol 2012;63:369-96.

5 Roos E, Lahelma E, Saastamoinen P, et al. The association of employment status and family status with health among women and men in four Nordic countries. Scand J Public Health 2005;33:250-60.

6 Schuring M, Robroek SJW, Lingsma HF, et al. Educational differences in trajectories of self-rated health before, during, and after entering or leaving paid employment in the European workforce. Scand J Work Environ Health 2015;41:441-50.

7 Thomas C, Benzeval M, Stansfeld SA. Employment transitions and mental health: an analysis from the British household panel survey. $J$ Epidemiol Community Health 2005;59:243-9.

8 Varekamp I, van Dijk FJH, Kroll LE. Workers with a chronic disease and work disability. Bundesgesundheitsblatt Gesundheitsforschung Gesundheitsschutz 2013;56:406-14.

9 Pedron S, Emmert-Fees K, Laxy M, et al. The impact of diabetes on labour market participation: a systematic review of results and methods. BMC Public Health 2019;19:25. 
10 Leal J, Luengo-Fernández R, Gray A, et al. Economic burden of cardiovascular diseases in the enlarged European Union. Eur Heart $J$ 2006;27:1610-9.

11 Schofield DJ, Callander EJ, Shrestha RN, et al. Multiple chronic health conditions and their link with labour force participation and economic status. PLoS One 2013;8:e79108.

12 Schofield DJ, Callander EJ, Shrestha RN, et al. Association between co-morbidities and labour force participation amongst persons with back problems. Pain 2012;153:2068-72.

13 Huber CA, Szucs TD, Rapold R, et al. Identifying patients with chronic conditions using pharmacy data in Switzerland: an updated mapping approach to the classification of medications. BMC Public Health 2013;13:1030.

14 Zhan C, Miller MR. Administrative data based patient safety research: a critical review. Qual Saf Health Care 2003:12 Suppl 2:58ii-63.

15 Andersen I, Brønnum-Hansen H, Kriegbaum M, et al. Increasing illness among people out of labor market - A Danish register-based study. Soc Sci Med 2016;156:21-8.

16 Virtanen M, Kivimäki M, Ferrie JE, et al. Temporary employment and antidepressant medication: a register linkage study. J Psychiatr Res 2008;42:221-9.

17 World Health O. Who collaborating centre for drug statistics methodology: ATC classification index with DDDs and guidelines for ATC classification and DDD assignment. Oslo, Norway: Norwegian Institute of Public Health, 2006.

18 Luo J, Qu Z, Rockett I, et al. Employment status and self-rated health in north-western China. Public Health 2010;124:174-9.

19 Stankunas M, Kalediene R, Starkuviene S, et al. Duration of unemployment and depression: a cross-sectional survey in Lithuania. BMC Public Health 2006;6:174.

20 Khlat M, Sermet C, Le Pape A. Increased prevalence of depression, smoking, heavy drinking and use of psycho-active drugs among unemployed men in France. Eur J Epidemiol 2004;19:445-51.
21 Ford E, Clark C, McManus S, et al. Common mental disorders, unemployment and welfare benefits in England. Public Health 2010;124:675-81.

22 Broomhall HS, Winefield $\mathrm{AH}$. A comparison of the affective wellbeing of young and middle-aged unemployed men matched for length of unemployment. Br J Med Psychol 1990;63:43-52.

23 Jackson PR, Warr PB. Unemployment and psychological ill-health: the Moderating role of duration and age. Psychol Med 1984;14:605-14.

24 Lahelma E. Unemployment, re-employment and mental well-being. A panel survey of industrial jobseekers in Finland. Scand J Soc Med Suppl 1989;43:1-170.

25 Sostres C, Gargallo CJ, Arroyo MT, et al. Adverse effects of nonsteroidal anti-inflammatory drugs (NSAIDs, aspirin and coxibs) on upper gastrointestinal tract. Best Pract Res Clin Gastroenterol 2010;24:121-32.

26 Atchison JW, Herndon CM, Rusie E. NSAIDs for musculoskeletal pain management:current perspectives and novel strategies to improve safety. J Manag Care Pharm 2013;19:S3-19.

$27 \mathrm{Li} \mathrm{CY}$, Sung FC. A review of the healthy worker effect in occupationa epidemiology. Occup Med 1999;49:225-9.

28 Jahoda M. Employment and unemployment. Cambridge University Press, 1982.

29 Bound J. Self-Reported versus objective measures of health in retirement models. J Hum Resour 1991;26:106-38.

30 Schuring M, Robroek SJ, Burdorf A. The benefits of paid employment among persons with common mental health problems: evidence for the selection and causation mechanism. Scand J Work Environ Health 2017;43:540-9.

31 van der Noordt M, IJzelenberg $\mathrm{H}$, Droomers $\mathrm{M}$, et al. Health effects of employment: a systematic review of prospective studies. Occup Environ Med 2014;71:730-6. 